\title{
CRESCIMENTO E COMPOSIÇÃO MINERAL DO PORTA-ENXERTO TANGERINEIRA CLEÓPATRA CULTIVADO EM SUBSTRATO ACRESCIDO DE POLÍMERO HIDRORRETENTOR
}

\author{
Growth and mineral composition of the Cleópatra mandarin rootstock \\ growing on substratum added with hidroretentive polymers
}

\author{
Marcelo Vichiato ${ }^{1}$, Mívia R. de Medeiros Vichiato ${ }^{2}$, Carlos Ramirez de R. e Silva ${ }^{3}$
}

\begin{abstract}
RESUMO
Os efeitos de polímero hidrorretentor acrescido ao substrato foi avaliado na fase inicial de produção do portaenxerto tangerineira 'Cleópatra' cultivado em tubetes plásticos com substrato comercial à base de casca de Pinus compostada e parcialmente fertilizado. Foi utilizado o delineamento experimental de blocos casualizados com três repetições, sendo os tratamentos seis doses do hidrorretentor $\left(0,4,8,12,16\right.$ e $\left.32 \mathrm{mg} . \mathrm{dm}^{-3}\right)$ incorporado ao substrato, com 60 plantas úteis por parcela. Avaliaram-se o Índice de Velocidade de Emergência (IVE), altura de planta, peso da matéria seca total e seus teores de N, $\mathrm{P}, \mathrm{K}, \mathrm{Ca}, \mathrm{Mg}, \mathrm{S}, \mathrm{B}, \mathrm{Cu}, \mathrm{Mn}, \mathrm{Zn}$ e Fe, e valores de $\mathrm{pH}$ do substrato ao final do período experimental. A incorporação do hidrorretentor ao substrato de cultivo promoveu elevação nos valores do $\mathrm{pH}$ do substrato, decréscimos no IVE, no crescimento e no peso da matéria seca total, não havendo alteração expressiva no estado nutricional dos porta-enxertos aos 150 dias pós-semeadura.
\end{abstract}

Termos para indexação: Citros, hidrorretentor, poliacrilato, condicionador de solo, muda.

\begin{abstract}
The effects of hidroretentive polymers added to the substratum was evaluated in the initial phase of production of 'Cleópatra' mandarin rootstock. They were cultivated in container seedlings with commercial pine bark substratum composted and partially fertilized. The randomized blocks experimental design was used with three replications, being the treatments six doses of the hydroretentive polymer $\left(0,4,8,12,16\right.$ and $\left.32 \mathrm{mg} \cdot \mathrm{dm}^{-3}\right)$ incorporated to the substratum. The Index of Emergency Speed (IVE), plant height, weight of the matter total drought and their tenors of N, P, K, Ca, Mg, S, B, Cu, Mn, Zn and Fe, and values of $\mathrm{pH}$ substratum were evaluated. The use of incorporated hydroretentive polymer to the cultivation substratum increased the values of $\mathrm{pH}$ of the substratum, decreases in IVE, the growth and the weight of the total dry matter, not having expressive alteration in the nutritional state of the rootstocks.
\end{abstract}

Index terms: Citrus, hydrogel, poliacrilate, soil conditioner, nursery plant.

(Recebido para publicação em 11 de setembro de 2003 e aprovado em 25 de novembro de 2003)

\section{INTRODUÇÃO}

Adubações nitrogenadas são as principais e mais críticas nos programas de fertilização em sementeiras de citros em ambientes controlados, onde há alta densidade de plantas e rápido crescimento vegetativo, sendo necessário aumentar a eficiência de aplicação dos fertilizantes para reduzir os custos de produção e minimizar a contaminação da água do subsolo (MAUST e WILLIANSOM, 1994). A intensa lavagem do substrato dos tubetes utilizados como sementeiras, aliada ao volume reduzido desses recipientes, leva a perdas significativas de alguns nutrientes, principalmente nitrogênio. No cultivo em recipientes, a limitação do vo- lume exige que o substrato seja capaz de manter água facilmente disponível às plantas sem, no entanto, comprometer a concentração de oxigênio no meio (FERMINO, 2002).

Uma adequada disponibilidade de água e nutrientes no substrato é necessária ao bom crescimento de porta-enxertos em tubetes. Outras características são desejáveis, tais como baixa densidade, boa aeração e drenagem, elevada capacidade de troca de cátions, boa coesão entre partículas ou aderência junto às raízes e ser preferencialmente um meio estéril (MELLO, 1989). Tem-se buscado a obtenção de substratos que atendam a essas qualidades, principalmente a maior retenção de água sem alteração das demais características. Uma

\footnotetext{
1. Engenheiro Agrônomo, Doutorando em Agronomia-Fitotecnia na Universidade Federal de Lavras/UFLA - Caixa Postal 37 - $37200-000$ - Lavras, MG. vichiato@hotmail.com.

2. Bióloga, Doutoranda em Agronomia-Fitotecnia na UFLA. mivia@ig.com.br.

3. Engenheiro Agrônomo, Dr., Professor do Departamento de Agricultura da UFLA.
} 
possível alternativa seria a adequação do uso de hidrorretentores (hidrorretentores) incorporados aos substratos. Esses são produtos naturais (derivados do amido) ou sintéticos (derivados do petróleo), utilizados por sua habilidade em absorver e armazenar água. São de forma granular e quebradiços quando secos, e se tornam macios e elásticos após expandidos na água. Os hidrorretentores mais freqüentemente usados são os polímeros sintéticos propenamida (poliacrilamida ou PAM) e os co-polímeros propenamida-propenoato (poliacrilamidaacrilato ou PAA) (MORAIS, 2001). Esses compostos absorvem muitas vezes seu peso em água, potencialmente liberando-a para o uso da planta, sendo recomendados para uso em transplante de mudas, adição a sementes e em substratos de vasos. A adição desses ao meio de cultivo de plantas freqüentemente aumenta a capacidade de retenção de água e o crescimento das plantas (TAYLOR e HALFACRE, 1986). Alguns hidrorretentores também são capazes de atuar como fornecedores de nutrientes, diminuir a fixação de fosfatos e a lixiviação de nutrientes, como potássio, magnésio e nitratos (NISSEN, 1994).

Alguns fatores influenciam o estado nutricional de plantas cultivadas com hidrorretentores, tais como: períodos prolongados de disponibilidade da solução de nutrientes, diminuição da lixiviação, capacidade de troca de cátions do polímero, capacidade de quelação do polímero, capacidade de tamponamento do $\mathrm{pH}$, e participação do polímero como fonte de nutrientes (TAYLOR e HALFACRE, 1986).

A quantidade de água retida pelos hidrorretentores pode ser negativamente afetada por químicos ou íons presentes na água (WANG e GREGG, 1990). Cátions como $\mathrm{Na}, \mathrm{Ca}$, e $\mathrm{Mg}$ reduzem sua absorção, sendo particularmente danosos à estrutura de todos os tipos de hidrorretentores.

Os polímeros hidrorretentores também têm a habilidade de promover o crescimento da planta quando nutrientes são incorporados a sua matriz, e assim liberá-los às plantas quando necessário. Entretanto, sob certas circunstâncias, sua adição tem tido pouca influência na performance das plantas, principalmente quando maiores quantidades de fertilizantes e sais estão presentes (Peterson, 2003). Swletlik (1989) concluiu não haver benefícios à produção de pomeleiros 'Ruby Red' (Citrus paradisi Macf.) recém-plantados. Ao contrário, em Ligustrum ludicum Ait 'Compactum', constatou-se que a interação entre hidrorretentor e nutrientes promoveu o crescimento, requerendo também irrigações menos freqüentes. As plantas apresentaram maiores níveis de $\mathrm{N}$ e $\mathrm{K}$ e menores níveis de $\mathrm{Ca}, \mathrm{Mg}$ e outros cátions divalentes, quando cultivadas em meio suplementado com os mesmos (TAYLOR e HALFACRE, 1986).

A retenção dos íons nitrato e amônio em substrato de areia adicionado de hidrorretentor foi verificada por Henderson e Hensley (1985). Em substrato seco, mais de $85 \%$ do amônio total adicionado ao meio foi retido como resultado da aplicação do hidrorretentor. Quando o substrato foi saturado com água antes da aplicação, a capacidade de retenção do íon amônio decresce a valores de $40 \%$ a $80 \%$. Em contraste ao amônio, o íon nitrato foi lixiviado rapidamente tanto em substrato seco como pré-hidratado, sendo ligeiramente maior nesse último. Os autores observaram que a maior retenção dos íons amônio no substrato seco indica que muitos pontos de absorção tornam-se indisponíveis quando o hidrorretentor adicionado se hidrata. Menor número de pontos de absorção permitiriam maior movimentação do íon amônio no meio hidratado. Verificaram ainda que essa propriedade poderia ser explorada em substratos com baixa capacidade de absorção, tais como casca de Pinus e agregados inertes, que provavelmente reteriam maiores quantidades de amônio. A capacidade dessas substâncias de reter fertilizantes e sais adicionados a sua matriz (WANG, 1989) poderia ser utilizada no cultivo de plantas em tubetes para maior disponibilização e economia dos fertilizantes aplicados.

Polímeros hidrorretentores foram pesquisados na produção de mudas de cafeeiros, apresentando resultados ambíguos. Incrementos em altura, massa seca da parte aérea e área foliar, e aumento nos intervalos entre as irrigações foram relatados por Azevedo (2000). Ação benéfica também foi por relatada por Calheiros et al. (2001), constatando maior armazenamento de água pelo solo, melhorando o estabelecimento e o desenvolvimento das plantas e diminuindo a morte por estresse hídrico. Entretanto, Mendonça et al. (2002), Lima et al. (2002) e Vallone (2003) não observaram resultados satisfatórios na produção de mudas de cafeeiro em tubetes, utilizando substrato comercial. Resultados negativos, como menor incremento em altura e área foliar, também foram relatados por Ferreira et al. (2002).

A interação de polímeros hidrorretentores com fertilizantes nitrogenados e potássicos no crescimento e nutrição do crisântemo (variedade Virgínia série globus) e nas características químicas dos substratos foi pesquisada por Sita (2002). A autora relatou influência negativa do polímero na absorção de nutrientes, bio- 
massa e produção de flores do crisântemo, o que contribuiu com o aumento de $\mathrm{K}$ e $\mathrm{N}$ nos substratos.

$\mathrm{Na}$ produção de mudas cítricas em tubetes, a adição de polímeros hidrorretentores como condicionadores do substrato ainda não foi relatada na literatura. A incorporação desses ao substrato promoveria a retenção de umidade e nutrientes, permitindo economia nas adubações com benefícios à nutrição dos porta-enxertos cítricos. Com este trabalho objetivou-se avaliar o efeito da adição de doses de polímero hidrorretentor ao substrato sobre o crescimento e o estado nutricional de porta-enxertos tangerineira 'Cleópatra' (Citrus reshni Hort. ex Tan) produzidos em tubetes.

\section{MATERIAL E MÉTODOS}

O experimento foi conduzido em casa-devegetação no Setor de Fruticultura da Universidade Federal de Lavras (UFLA), em Lavras-MG no período de 20/12/2002 a 30/05/2003. Os porta-enxertos tangerineira 'Cleópatra' (Citrus reshni Hort. ex Tan) foram semeados e cultivados em tubetes plásticos contendo substrato comercial Plantmax ${ }^{\circledR}$ à base de casca de Pinus moída, compostada e enriquecido com 1280 g.m ${ }^{-3}$ de $\mathrm{P}_{2} \mathrm{O}_{5}$. Esse se constitui de um farelado grosso com capacidade de retenção de água mínima de $150 \%$ em massa. Segundo dados de Calvete et al. (2002), o substrato Plantimax ${ }^{\circledR}$ possui composição de $20,16 \%$ de sólidos; 4,84\% de espaço de aeração; 36,3\% de água disponível e $38,70 \%$ de água retida.

Foi utilizado o delineamento experimental em blocos casualizados com três repetições e unidade experimental com 60 plantas úteis. Os tratamentos foram constituídos de seis doses do hidrorretentor (Hydrossoloß) nas doses de 0, 4, 8, 12, 16 e 32 $\mathrm{mg} . \mathrm{cm}^{-3}$ ) adicionados ao substrato antes do plantio, baseadas na recomendação do fabricante de 4 a 6 $\mathrm{mg} \cdot \mathrm{cm}^{-3}$. Esse é caracterizado como um pó insolúvel em água, de baixa granulometria, inodoro, nãoinflamável, não-perecível, atóxico, de cor acinzentada, $\mathrm{pH}$ entre 5,0 e 5,5, densidade aparente 1,2 a 1,4 $\left(\mathrm{g} / \mathrm{cm}^{3}\right)$ e peso específico de 2,6 a $2,9\left(\mathrm{~g} / \mathrm{cm}^{3}\right)$. Contém 0,3 a 0,4 dag. $\mathrm{kg}^{-1}$ de $\mathrm{Mg} ; 0,01$ a 0,02 dag. $\mathrm{kg}^{-1}$ de $\mathrm{Cu} ; 0,01$ a 0,02 dag. $\mathrm{kg}^{-1}$ de $\mathrm{Zn} ; 0,01$ a 0,02 dag. $\mathrm{kg}^{-1}$ de Mo e 0,01 a 0,02 dag. $\mathrm{kg}^{-1}$ de Fe.

Foram semeadas três sementes por tubete (volume de $50 \mathrm{~cm}^{3}$ ), com desbaste aos 53 dias após a semeadura, deixando uma plântula por tubete e iniciando-se adubações nitrogenadas à base de uréia, via água de irrigação, na dose $1170 \mathrm{mg} \cdot \mathrm{dm}^{-3}$ de $\mathrm{N}$ no substrato.
A adubação foi parcelada em oito aplicações em intervalos de sete dias, com cada tubete recebendo $5 \mathrm{ml}$ de solução, conforme resultados de Decarlos Neto et al. (2002).

As irrigações foram efetuadas manualmente com regador, suficientes para manutenção da umidade do substrato dos tubetes em $70 \%$ da capacidade de campo (calculada com base na curva de retenção de água no substrato), e aferida diariamente por pesagens dos tubetes amostrados nas parcelas de cada tratamento. Essa metodologia foi adotada por Vallone (2003) e Francescato (1995), mostrando-se satisfatória para reposição de água e avaliação do desenvolvimento de mudas de cafeeiro e do porta-enxerto limoeiro 'Cravo', respectivamente.

A partir do vigésimo dia após a semeadura, procedeu-se ao acompanhamento diário da emergência das plântulas para estimativa do índice de velocidade de emergência (IVE) e, aos 150 dias após a semeadura, avaliou-se a altura de planta nas parcelas úteis, e nas amostras coletadas, foram determinados o peso da matéria seca total e os teores foliares de $\mathrm{N}, \mathrm{P}, \mathrm{K}, \mathrm{Ca}, \mathrm{Mg}$, $\mathrm{S}, \mathrm{B}, \mathrm{Cu}, \mathrm{Fe}, \mathrm{Mn}$ e $\mathrm{Zn}$. Foram retiradas amostras do substrato para determinação dos valores de $\mathrm{pH}$ ao final do experimento. Os dados obtidos foram submetidos à análise de variância utilizando níveis de significância de $1 \%$ e $5 \%$ de significância pelo Teste F, e para as médias com diferenças significativas, procedeu-se à análise de regressão polinomial.

\section{RESULTADOS E DISCUSSÃO}

O acréscimo de hidrorretentor ao substrato promoveu diminuição no vigor das sementes, avaliado pelo índice de velocidade de emergência (IVE), obtendo-se valores superiores para o tratamento testemunha (Figura 1-A). Esse efeito prejudicial promovido pelo aumento das doses do hidrorretentor no substrato foi, possivelmente, devido à diminuição do espaço de aeração no substrato em função da característica de expansão dos grânulos do polímero hidrorretentor em contato com a água das irrigações, o que reduziu a taxa respiratória durante os eventos pré-germinativos. $\mathrm{O}$ crescimento em altura (Figura 1-B), avaliado 150 dias após a semeadura, foi também prejudicado provavelmente pela menor aeração do sistema radicular, o que compromete a absorção iônica e a disponibilidade de nutrientes. A deficiência nutricional é um dos fatores que limita o crescimento de plantas em substrato pobre em aeração (FAQUIN, 1994). 
Os maiores valores para altura das plantas foram observados nos tratamentos com menores doses do hidrorretentor, com pequena superioridade das doses $4 \mathrm{mg} \cdot \mathrm{cm}^{-3}$ e $8 \mathrm{mg} \cdot \mathrm{cm}^{-3}$, sem importância do ponto de vista prático. Ademais, esses resultados são inferiores ao relatado por Decarlos Neto et al. (2002), de $12 \mathrm{~cm}$, aos 120 dias após a semeadura e por Vichiato et al. (1998), com altura média de 14,5 cm aos 135 dias após a semeadura, não se constando, portanto, benefícios da adição do hidrorretentor para ganhos no crescimento das plantas. Esses resultados são devidos ao menor ritmo de crescimento das plantas em função dos fatores já mencionados e ao uso de substratos alternativos ao utilizado no trabalho, tais como compostos de esterco animal, vermiculita expandida e terriço. Esse mesmo substrato comercial foi utilizado na produção de mudas de cafeeiro, também apresentando resultados negativos nas características de crescimento das mudas e na capacidade de armazenamento de água com adição de hidrorretentores ao substrato (VALLONE, 2003). Esse autor, comparando o armazenamento de água desse substrato comercial à base de casca de pinus compostada com outro de casca de arroz carbonizada pura ou em misturas, constatou ser o substrato comercial o de menor capacidade de armazenamento de água e o que apresentou o menor benefício com acréscimo do hidrorretentor.

Constatou-se tendência de decréscimos no peso da matéria seca total dos porta-enxertos com aumento nas doses do hidrorretentor (Figura 2-A). Os maiores valores foram observados nos tratamentos 8 $\mathrm{mg} \cdot \mathrm{cm}^{-3}$ e $4 \mathrm{mg} . \mathrm{cm}^{-3}$ de hidrorretentor, superiores à testemunha, e à semelhança do observado nas alturas das plantas.
Sita (2000) também relatou decréscimos na produção de biomassa por plantas de crisântemo cultivadas com polímero hidrorretentor, assim como Vallone (2003), que testou doses semelhantes às deste trabalho, atribuindo-se esse comportamento à deficiência em aeração do substrato, como já mencionado para as outras características de crescimento. Apesar dos baixos valores dos coeficientes de determinação das equações de regressão, a não-significância dos desvios de regressão não invalida os modelos ajustados.

A adição de doses do hidrorretentor promoveu elevação nos valores de $\mathrm{pH}$ do substrato de 5,3 até 6,7 faixa de maior disponibilidade de nutrientes essenciais para as plantas (Figura 2-B). Essa elevação pode ser devida à alteração da capacidade de troca de cátions (CTC) do substrato proporcionada pelo hidrorretentor adicionado ao mesmo, possivelmente pela maior retenção de cátions básicos. A CTC do hidrorretentor é muito alta quando comparada à maioria dos tipos de solo (MORAIS, 2001).

Os teores foliares de N, P, Ca, B, Mn, Zn e Fe foram influenciados pela adição de hidrorretentor ao substrato (Tabela 1).

Os níveis de $\mathrm{N}$ apresentaram variação de 1,99 a 2,73 dag. $\mathrm{kg}^{-1}$; apesar das diferenças evidenciadas pela análise de regressão, não houve o incremento esperado com a aplicação do hidrorretentor, sendo o tratamentotestemunha o que apresentou os maiores valores médios.

Esses valores são semelhantes aos observados por Vichiato et al. (1998), e superiores ao relatado por Decarlos Neto et al. (2002) como teores adequados de $\mathrm{N}$-total na matéria seca da parte aérea para $90 \%$ e $100 \%$ do crescimento máximo em altura dos porta-

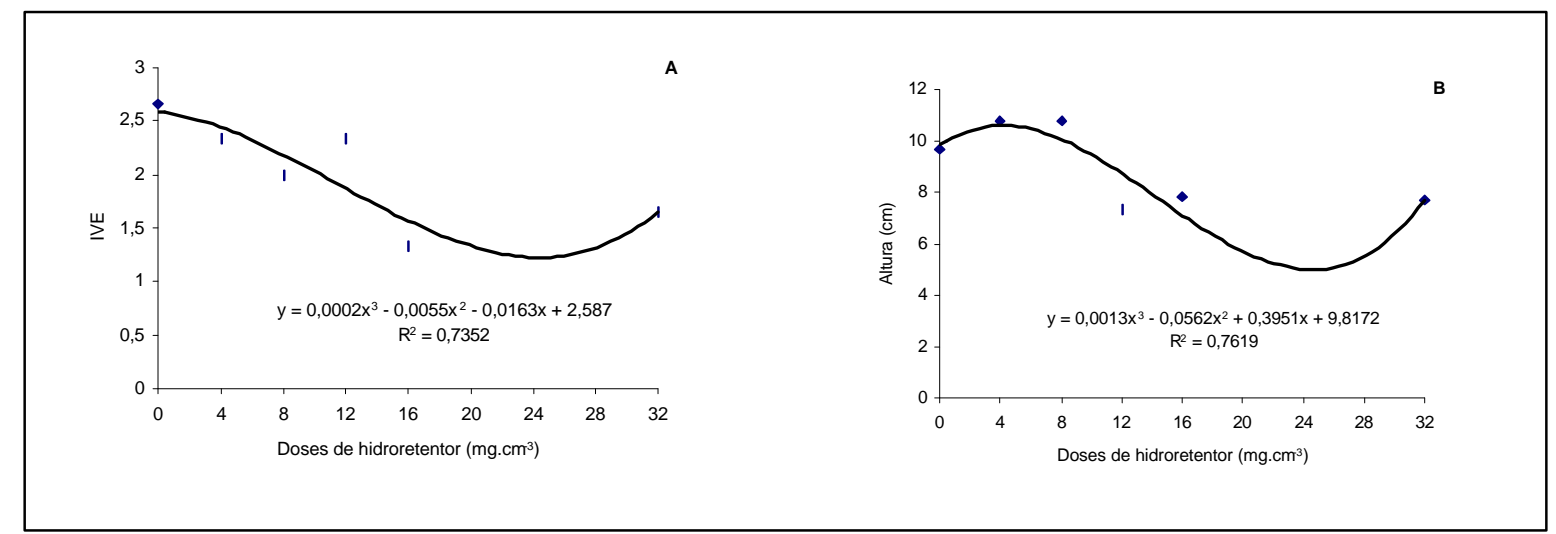

FIGURA 1 - Índice de Velocidade de emergência de plântulas (A) e altura (B) de tangerineiras 'Cleópatra' em relação à adição de doses de hidrorretentor ao substrato. UFLA, Lavras, 2002. 
enxertos (1,7 a 2 dag. $\left.\mathrm{kg}^{-1}\right)$. Os valores são superiores por serem expressos com base na matéria seca total dos porta-enxertos, sendo esses valores também concordantes com os de Carvalho (1994).

A faixa do teor adequado de $\mathrm{N}$-total na matéria seca da parte aérea dos porta-enxertos representa uma condição ótima de crescimento dos porta-enxertos, podendo ser utilizada como critério de necessidade de $\mathrm{N}$ (DECARLOS NETO et al., 2002). Taylor e Halfacre (1986) verificaram que níveis de N e K superiores foram observados em todos os tecidos das plantas tratadas com hidrorretentor, em comparação com as plantas não-tratadas. Neste trabalho, os níveis de K não foram afetados, sendo os de $\mathrm{N}$ do tratamento testemunha superiores aos demais tratamentos. Os valores inferiores dos tratamentos adicionados de hidrorretentor podem ser devidos à menor aeração do substrato, que prejudica a absorção, mesmo com um possível aumento na disponibilidade de íons amônia. Mais de $85 \%$ do total do amônio aplicado pode ser retido com doses de até $4 \mathrm{~kg} / \mathrm{m}^{3}$ de hidrorretentor adicionadas a substrato de areia, sendo o comportamento dos íons amônio e nitrato similares àqueles esperados no solo (HENDERSON e HENSLEY, 1985).

A concentração de Ca nos tecidos aumentou com o acréscimo nas doses, resultado discordante de Taylor e Halfacre (1986), que observaram decréscimos nos teores de Ca na parte aérea da espécie Ligustrum lucidum. Esse aumento de 1,47 a 1,68 pode ser devido à maior disponibilidade do nutriente em função do aumento no $\mathrm{pH}$ do substrato $(5,3$ a 6,7$)$ proporcionado pelos tratamentos, o que poderia explicar também o comportamento dos níveis de $\mathrm{P}$ nas maiores doses (Figura 3). A maior disponibilidade de Ca nos maiores valores de $\mathrm{pH}$ poderia afetar a absorção de $\mathrm{P}$, que se torna menos disponível pela precipitação com Ca em $\mathrm{pH}$ 's próximos a 7,0 .

Os teores de B, Fe, Mn e Zn em função das doses de hidrorretentor estão representados na Figura 4. Os teores de Mn decresceram com o aumento nas doses do hidrorretentor, efeito também observado por Taylor e Halfacre (1986) e Wallace et al. (1986). Cátions divalentes podem ser fixados formando ligações com grupos carboxil, amido ou carbonil ao longo da estrutura do polímero, tornando alguns íons indisponíveis para a planta. $\mathrm{O}$ aumento do $\mathrm{pH}$ já relatado também poderia reduzir a disponibilidade de Mn e Zn no substrato.

Os níveis de Boro nos tecidos foram inferiores aos do tratamento-testemunha, porém, sem uma tendência definida, similarmente ao ocorrido com os teores de Ferro que, no entanto, apresentaram-se muito superiores ao relatado na literatura, mesmo naqueles trabalhos em que substratos de composição semelhante foram utilizados, de 512 ppm (VICHIATO et al., 1998) e 580 ppm. Decréscimos nos teores de $\mathrm{B}$ e $\mathrm{Fe}$ foram relatados no cultivo de trigo e tomate com hidrorretentores (WALLACE et al., 1986).

Apesar da influência exercida na absorção de alguns nutrientes com a adição do hidrorretentor ao substrato, os valores observados são semelhantes aos relatados na literatura para porta-enxertos nessa fase do crescimento, não representando, portanto, alteração significativa na nutrição mineral dos porta-enxertos, mostrando, porém, efeito detrimental ao crescimento vegetativo desses.

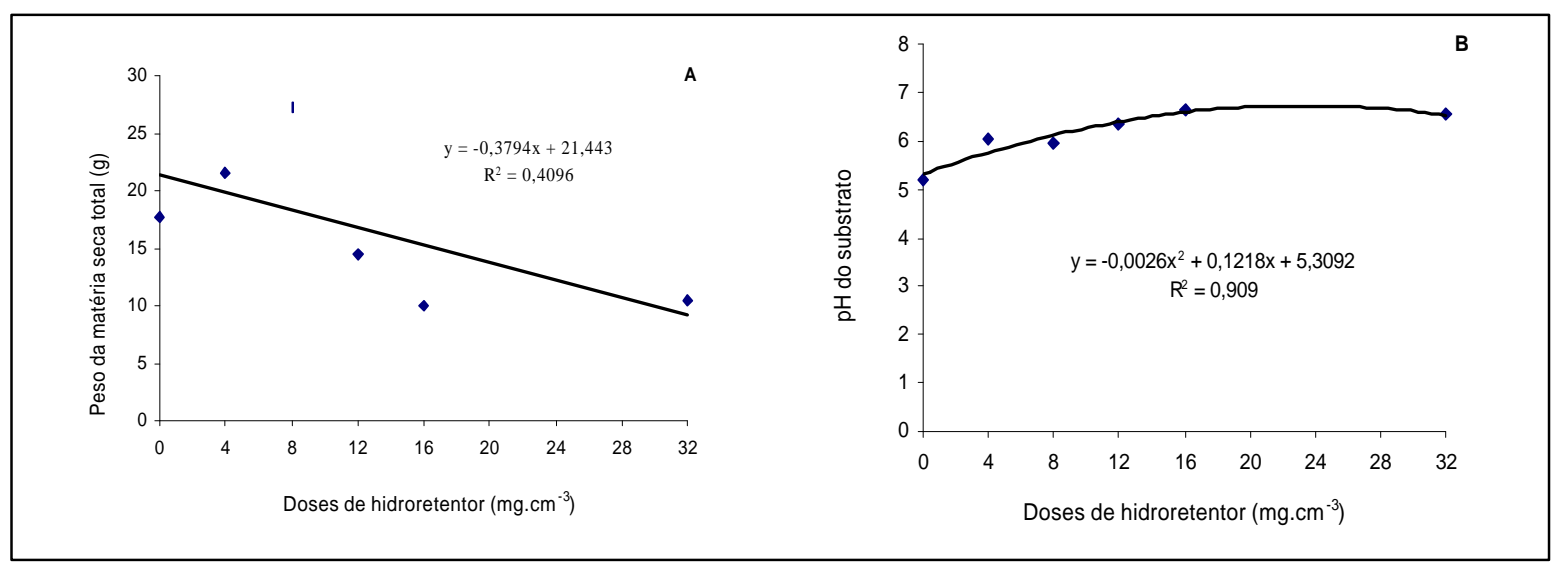

FIGURA 2 - Peso da matéria seca total de tangerineiras 'Cleópatra' (A) e pH do substrato (B) em relação à adição de doses de hidrorretentor ao substrato. UFLA, Lavras, 2002. 


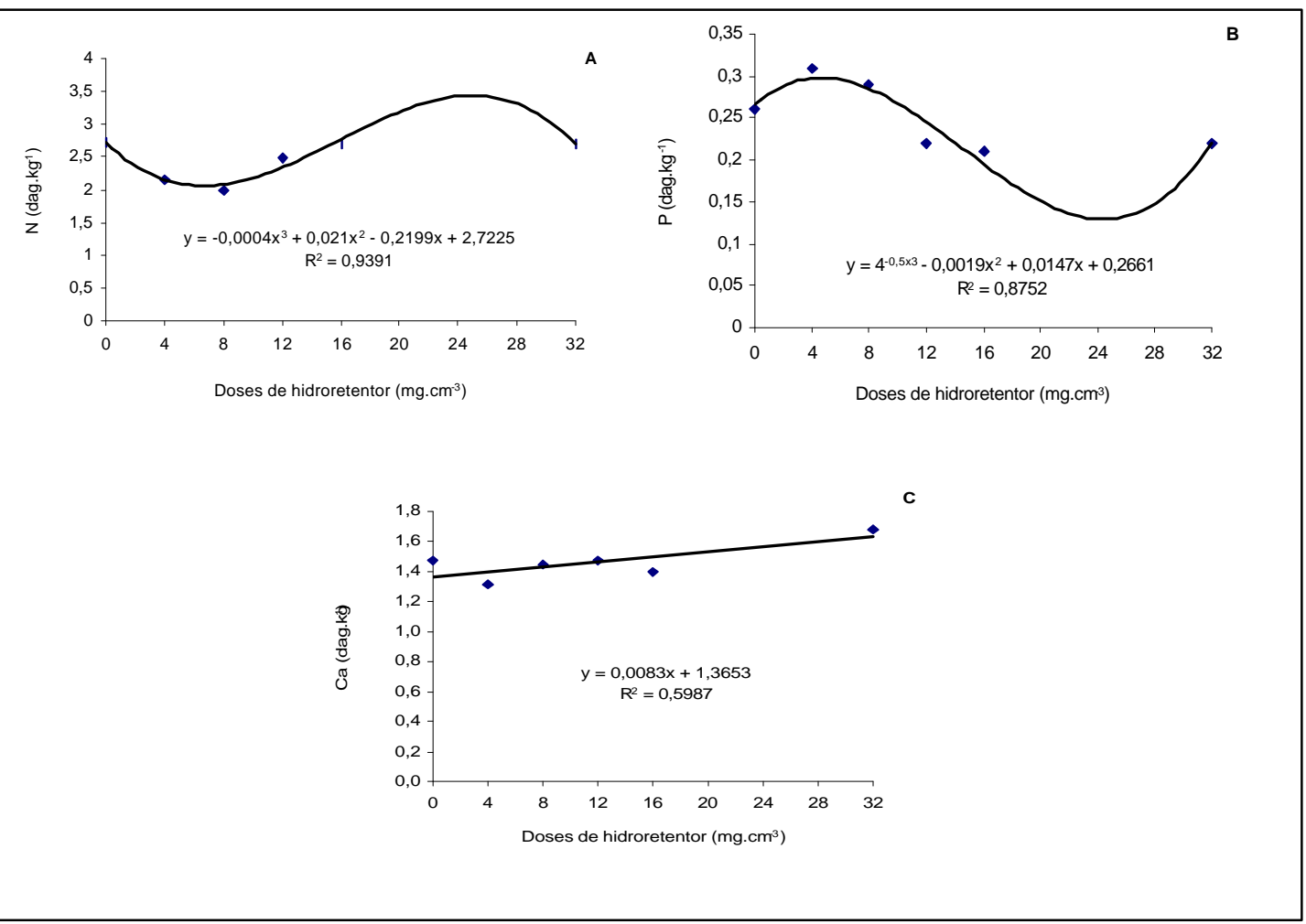

FIGURA 3 - Teores de nitrogênio (A), fósforo (B) e cálcio (C) na matéria seca total de tangerineiras 'Cleópatra' em relação à adição de doses de hidrorretentor ao substrato. UFLA, Lavras, 2002.

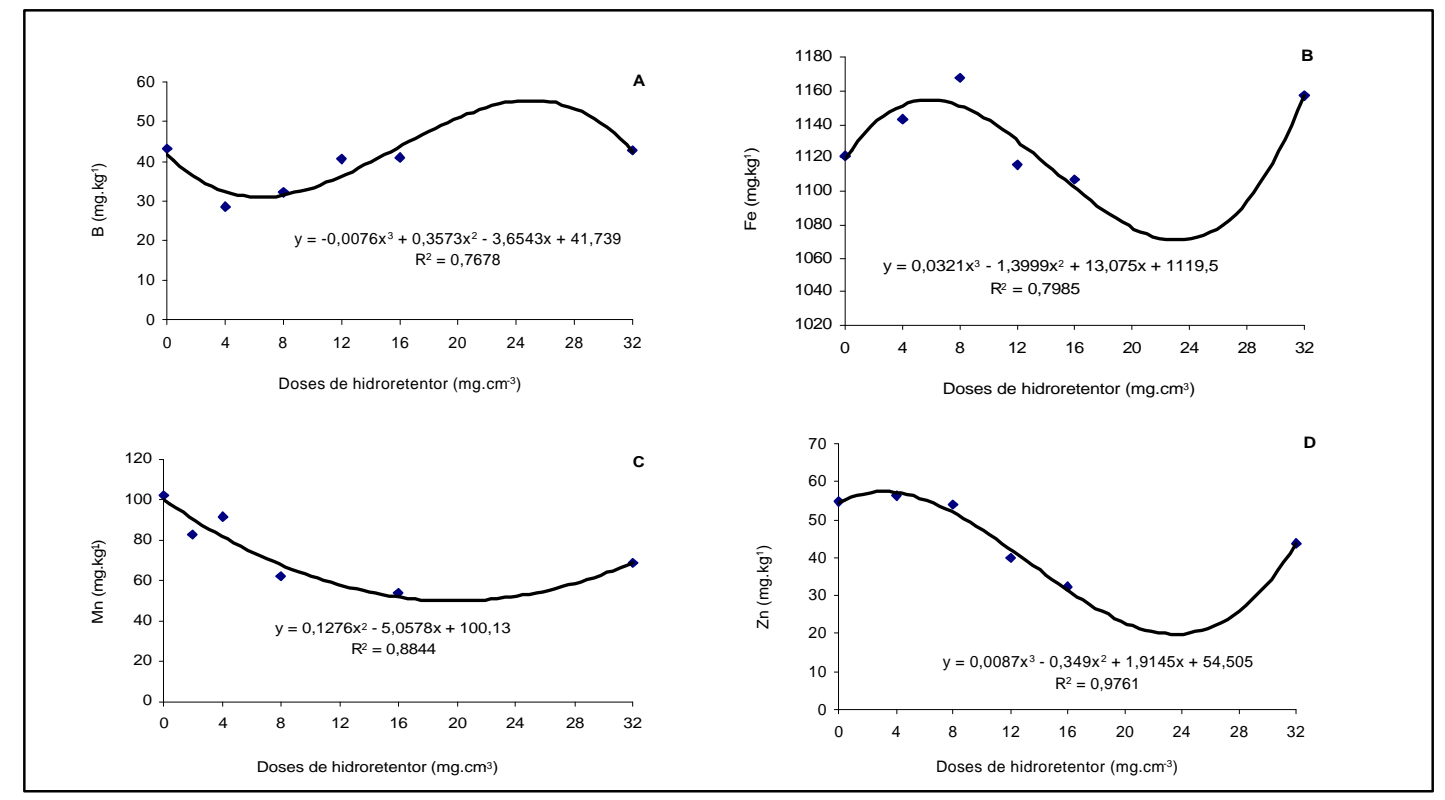

FIGURA 4 - Teores de boro (A), ferro (B) manganês (C) e zinco (D) na matéria seca total de tangerineiras 'Cleópatra’ em relação à adição de doses de hidrorretentor ao substrato. UFLA, Lavras, 2002. 


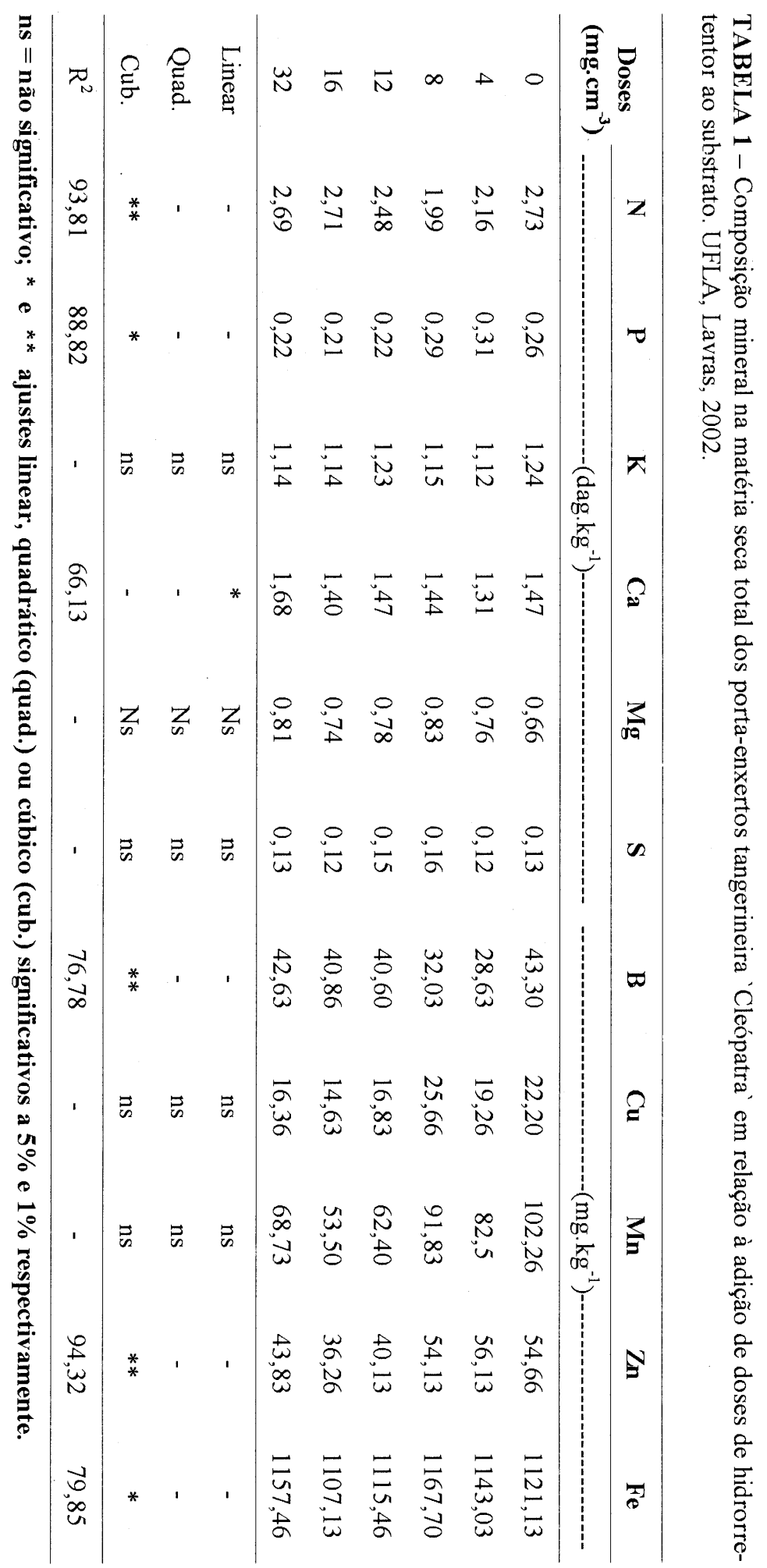

Ciênc. agrotec., Lavras, v. 28, n. 4, p. 748-756, jul./ago., 2004 


\section{CONCLUSÕES}

A incorporação do hidrorretentor ao substrato é prejudicial ao desenvolvimento vegetativo, sem, entretanto, alterar o estado nutricional dos porta-enxertos tangerineira 'Cleópatra` cultivados em tubetes até a fase de repicagem.

\section{REFERÊNCIAS BIBLIOGRÁFICAS}

AZEVEDO, T. L. F. Avaliação da eficiência do polímero agrícola de poliacrilamida no fornecimento de água para o cafeeiro (Coffea arabica L.) cv. Tupi. 2000. 38 f. Dissertação (Mestrado) - Universidade Estadual de Maringá, Maringá, 2000.

CALHEIROS, R. de O.; ARRUDA, F. B.; SAKAI, E.; PIRES, R. C. de M.; BORTOLETO, N. Efeito de condicionador hídrico nas características físico-hídricas do solo, no estabelecimento de mudas de café e na relação solo-água-planta. In: CONGRESSO BRASILEIRO DE PESQUISAS CAFEEIRAS, 25., 2001, Uberaba-MG. Trabalhos apresentados... Rio de Janeiro: MA/ PROCAFE, 2001. p. 398-401.

CALVETE, E. O.; KLEIN, V. A.; BORDIGNON, L. Avaliação de substratos para cultivo do morangueiro fora do solo. In: FURLANI, A. M. C. (Coord.). Caracterização, manejo e qualidade de substratos para produção de plantas. Campinas: Instituto Agronômico, 2002. 122 p. (Documentos IAC, 70).

CARVALHO, S. A. de. Manejo da adubação nitrogenada na produção de porta-enxertos cítricos em bandejas. 1994. 95 f. Tese (Doutorado em Fitotecnia) Escola Superior de Agricultura de Lavras, Lavras, 1994.

DECARLOS NETO, A.; SIQUEIRA, D. L. de; PEREIRA, P. R. G.; ALVAREZ, V. H. Crescimento de porta-enxertos de citros em tubetes influenciados por doses de N. Revista Brasileira de Fruticultura, Jaboticabal, v. 24, n. 1, p. 199-203, 2002.

FAQUIN, V. Nutrição mineral de plantas. Lavras: FAEPE, 1994. 227 p.

FERMINO, M. H. O uso da análise física na avaliação da qualidade de componentes e substrato. In: FURLANI, A. M. C. Caracterização, manejo e qualidade de substratos para produção de plantas. Campinas: Instituto Agronômico, 2002. p. 29-37. (Documentos IAC, 70).
FERREIRA, R. de S.; VALLONE, H. S.; GUIMARÃES, R. J.; MELO, L. Q. de; CARVALHO, J. de A. Efeito de poliacrilato superabsorvente no desenvolvimento inicial do cafeeiro (Coffea arabica L.) em casa de vegetação sob diferentes níveis de déficit hídrico. In: CONGRESSO BRASILEIRO DE PESQUISAS CAFEEIRAS, 28., 2002, Caxambú, MG. Trabalhos apresentados... Rio de Janeiro: MA/PROCAFE. 2002. p. 202-204.

FRANCESCATO, R. D. C. Influência da freqüência de irrigação, substrato e adubo de liberação lenta na produção do porta-enxerto cítrico limão cravo (Citrus limonia Osbeck). 1995. $98 \mathrm{f}$. Dissertação (Mestrado em Fitotecnia) - Escola Superior de Agricultura Luiz de Queiróz, Piracicaba, 1995.

HENDERSON, J. C.; HENSLEY, D. L. Ammonium and nitrate retention by a hydrophilic gel. HortScience, Alexandria, v. 20, n. 4, Aug. 1985.

LIMA, L. M. L. de; FERNANDES, D. L.; ALMEIDA, F. G. de; MENDONÇA, F. C.; TEODORO, R. E. F. Utilização de hidrorretentor em substrato para produção de mudas de café, sob diferentes lâminas de irrigação. In: SIMPÓSIO BRASILEIRO DE PESQUISA EM CAFEICULTURA IRRIGADA, 5., 2002, Araguari, MG. Anais... Uberlândia: UFU, 2002. p. 37-41.

MAUST, B. E.; WILliANSOM, J. G. Nitrogen nutrition of containerized citrus nursery plants. Journal of American Society for Horticultural Science, Alexandria, v. 119, n. 2, p. 195-201, 1994.

MELO, A. C. G. de. Efeito de recipientes e substratos no comportamento silvicultural de plantas de Eucalyptus grandis Hill ex Maiden e do Eucalyptus urophylla S.T. Blake. 1989. 80 f. Dissertação (Mestrado em Ciências Florestais) - Escola Superior de Agricultura Luiz de Queiróz, Piracicaba, 1989.

MENDONÇA, C. M.; TEODORO, R. E. F.; LIMA, L. M. L. de; FERNANDES, D. L.; CORDEIRO, M. G.; NOVAES, Y. N. Produção de mudas de caFe (Coffea arabica L.) cv. Acaiá em tubetes com polímero hidroabsorvente adicionado ao substrato. In: SIMPÓSIO BRASILEIRO DE PESQUISA EM CAFEICULTURA IRRIGADA, 5., 2002, Araguari, MG. Anais... Uberlândia: UFU, 2002. p. 167-171. 
MORAIS, O. Efeito do uso de polímero hidrorretentor no solo sobre o intervalo de irrigação na cultura da alface (Lactuca sativa L.). 2001. 73 f. Tese (Doutorado em Irrigação e Drenagem) - Escola Superior de Agricultura Luis de Queiróz, Piracicaba, 2001.

NISSEN, M. J. Uso de hidrorretentores em la producción de frambuesas (Rubus idaeus) del sur de Chile. AgroSur, Valdivia, v. 22, n. 2, p. 160-165, 1994.

PETERSON, D. Hydrophilic polymers: effects and uses in the landscape. 2003. Disponível em: <http://www.hort.agri.umn.edu/h5015/01 papers/hydrog el.htm>. Acesso em: 29 jul. 2003.

SITA, R. C. M. Influência das formas de adubação nitrogenada e potássica na ação do polímero hidrorretentor sobre o crescimento de crisântemo (Dendranthema grandiflora) var. "Virginal". 2002. Disponível em <http://www.prppg.ufpr.br/documentos/ stricto/solos/solos-resumos.rtf $>$. Acesso em: 20 set. 2003.

SWLETLIK, D. Effect of soil amendment with Viterra hydrogel on stablishment of newly planted grapefruit trees cv. 'Ruby Red'. Communications in Soil Science and Plant Analysis, New York, v. 20, n. 15/16, p. 1697-1705, 1989

TAYLOR, K. C.; HALFACRE, R. G. The effect of hydrophilic polymer on media water retention and nutrient availability to Ligustrum lucidum. HortScience, Alexandria, v. 21, n. 5, oct. 1986.

VALLONE, H. S. Produção de mudas de cafeeiro (Coffea arábica L.) em tubetes com polímero hidrorretentor, diferentes substratos e adubações. 2003. 75 p. Dissertação (Mestrado em Agronomia-Fitotecnia) Universidade Federal de Lavras, Lavras, 2003.

VICHIATO, M.; SOUZA, M. de; AMARAL, A. M. do; MEDEIROS, M. R. de; RIBEIRO, W. G. Desenvolvimento e nutrição mineral da tangerineira Cleópatra fertilizada com superfosfato simples e nitrato de amônio em tubetes até a repicagem. Ciência e Agrotecnologia, Lavras, v. 22, n. 1, p. 30-41, jan./mar. 1998.

WALLACE, A.; WALLACE, G. A.; ABOUZAMZAM, A. M. Effects of excess levels of a polymer as a soil conditioner on yields and mineral nutrition of plants. Soil Science, Madison, v. 141, n. 5, p. 377-380, 1986.

WANG, Y. T. Médium and hydrogel affect production and wilting of tropical ornamental plants. HortScience, Alexandria, v. 24, n. 6, p. 941-944, 1989.

WANG, Y. T.; GREGG, L. L. Hydrophilic polymers: their response to amendments and effect on properties of a soilless potting mix. Journal of Americam Society for Horticultural Science, Alexandria, v. 115, p. 943-948, 1990. 